\title{
SANITASI EKOLOGIS IPAL SANIMAS DI KAMPUNG SANGKRAH SURAKARTA
}

\author{
Ronim Azizah, Adesta Ari Wibowo \\ Program Studi Teknik Arsitektur, Fakultas Teknik, Universitas Muhammadiyah Surakarta \\ Jl. A. Yani Tromol Pos 1 Pabelan Kartasura Sukoharjo 57102 Telp 0271-717417 \\ E-mail: ronimazizah@gmail.com
}

\begin{abstract}
ABSTRAK
Sangkrah merupakan kampung perkotaan yang padat dan kumuh yang memiliki sanitasi lingkungan yang buruk. Untuk memenuhi kebutuhan buang air besar masyarakat biasanya menggunakan sarana WC umum karena hanya sedikit warga yang memiliki km/wc. Saat ini Kampung Sangkrah telah menggunakan Sanimas (sanitasi berbasis masyarakat) sebagai lokasi percontohan pengelolaan sanitasi lingkungan yang buruk. Lokasi MCK berada di lokasi yang masyarakatnya bersedia untuk berpartisipasi dalam pembangunan Sanimas. Penelitian ini bertujuan untuk mengkaji sanitasi ekologis yang diterapkan pada IPAL Sanimas dan seberapa besar hasil pengolahannya dapat dimanfaatkan oleh masyarakat. Metode penelitian dengan cara observasi lapangan untuk: (1) pencarian data gambar dan data tekstual; dan (2) melakukan identifikasi sistim sanitasi pada IPAL SANIMAS. Hasil penelitian ini menunjukkan bahwa IPAL Sanimas di Kampung Sangkrah mampu mengatasi masalah sanitasi lingkungan yang buruk dengan cara: (1) membuat saluran pembuangan dari MCK secara terpisah antara grey water dan black water; (2) pembuangan limbah dari kloset (black water) diolah dengan biodigester yang menghasilkan gas metan sebagai bahan bakar memasak untuk membantu kegiatan sosial seperti Idul Adha; (3) limpahan air dari biodigester dan limbah grey water disalurkan ke bak settler, baffle reaktor dan anaerobik filter yang kemudian disalurkan ke sungai.
\end{abstract}

\section{Kata Kunci: sanitasi ekologis, IPAL, Sanimas}

\section{PENDAHULUAN \\ Latar Belakang}

Substansi secara spesifik tentang desain berkelanjutan atau ekologis antara lain: (1) tidak menghabiskan bahan lebih cepat daripada tumbuhnya kembali bahan tersebut oleh alam;(2) menggunakan energi terbarukan secara optimal; (3) menghasilkan limbah yang dapat dimanfaatkan sebagai sumber bahan baru (Frick ,2007).

Sanimas adalah program peningkatan kualitas sanitasi dengan teknologi sederhana dan murah yang dikelola oleh masyarakat khususnya diperuntukkan bagi kawasan padat, dengan sanitasi buruk dan miskin (http://ciptakarya.pu.go.id/plp/wsp/). Indonesia masih berada di peringkat 12 dari 18 negara di Asia dengan predikat negara dengan toilet kotor dan buruk. (http://www.borda-sea.org/fileadmin/bordasea/Knowledge/BORDA\%20Blitz/2012_3_1_B B\%238-web.pdf).

Kegiatan Sanimas sebagai percontohan ini dibiayai dengan sistim multi- sources of funding terdiri dari Pemerintah Pusat, Pemerintah Kota/Kabupaten, BORDA (Bremen Overseas Research And Development Association) dan Masyarakat. Kelembagaan Sanimas dibagi menjadi 2 yaitu Panitia Pembangunan dan Badan Pengelola. Kelembagaan Sanimas disebut sebagai Kelompok Swadaya Masyarakat (KSM) Sanimas. Tanggung jawab Kelompok Swadaya Masyarakat (KSM) Sanimas berupa: konstruksi, pengoperasian dan pemeliharaannya.

Kampung Sangkrah adalah salah satu kampung padat dan bersanitasi buruk yang 
menjadi percontohan dibangunnya Sanimas selain di Mojosongo, Joyotakan, Joyoraharja, Danukusuman, dan Semanggi. Pengguna Sanimas ditentukan oleh masyarakat sendiri dengan kriteria berdomisili di kampung tersebut dan diutamakan bagi warga yang belum memiliki jamban sendiri. Pemerintah Kota Surakarta melalui DPU pemerintah Kota Surakarta menurunkan fasilitator untuk melakukan survei kampung PAKUMIS (Padat Kumuh Miskin) dan salah satunya adalah daerah Sangkrah,Kecamatan Pasar Kliwon. Di Kampung Sangkrah terdapat 6 titik yang di survei namun fasilitator memilih 1 titik dengan pertimbangan bahwa kampung tersebut memiliki masyarakat yang ikut berpartisipasi. Lokasi tersebut terletak di RT.04 RW.08 Kelurahan Sangkrah, Kecamatan Pasar Kliwon. Pada tahun 2006, Pemerintah Kota Surakarta membentuk Sanimas "INSAN HARAPAN" di Kampung Sangkrah.

Dengan dibangunnya sarana Sanimas dari pendanaan Pemerintah Pusat, Pemerintah Kota/Kabupaten, BORDA dan masyarakat maka diharapkan mampu menyelesaikan masalah sanitasi yang buruk. Teknologi Sanimas yang dipilih masyarakat berupa MCK dan IPAL harus dapat dimanfaatkan secara maksimal oleh masyarakat Kelurahan Sangkrah. Berdasarkan kondisi tersebut maka perlu dikaji sejauhmana sanitasi ekologis yang diterapkan pada IPAL Sanimas di Kampung Sangkrah.

\section{Tinjauan Pustaka}

Menurut Yeang (2006), sanitasi ekologis adalah suatu sistim yang memanfaatkan limbah manusia dan mengubahnya menjadi sumber energi yang berharga yang dapat digunakan untuk pertanian tanpa menimbulkan polusi dan menghemat air serta mencegah pencemaran air. Sebuah alternatif lain pengolahan air limbah domestik untuk skala propinsi dan nasional adalah sistim DEWATS (Decentralized Wastewater treatment plant) melalui program Sanimas atau sanitasi berbasis masyarakat (Prihan-drijanti \& Firdayati, 2011). Sanimas adalah program peningkatan kualitas sanitasi dengan teknologi sederhana dan murah yang dikelola oleh masyarakat khususnya diperuntukkan bagi kawasan padat, dengan sanitasi buruk danmiskin (http://ciptakarya.pu.go.id/p/p/wsp/).
Terdapat 3 (tiga) model sanitasi berbasis masyarakat yaitu (Prihandrijanti \& Firdayati, 2011) :

1. Tangki septik komunal untuk 4 hingga 5 rumah tangga yang memiliki toilet sendiri dan terhubung dengan saluran ke tangki septik komunal.

2. Penambahan MCK komunal dengan pengolahan biogas dan pemakaian kembali.

3. Tersedia saluran pembuangan yang mengarah ke fasilitas pengolahan limbah komunal berbentuk baffle reactor (bak penyekat). Pada model ini setiap rumah tangga harus memiliki toilet dan disambungkan ke saluran pembuangan.

Beberapa teknologi dasar yang digunakan untuk pengolahan limbah adalah tangki septik dengan sistim resapan, anaerobic baffle reactor dan biofiltrasi.

(http://ciptakarya.pu.go.id/plp/wsp/).

Menurut Yeang (2006), sistim sanitasi ekologis yang berfungsi untuk mengolah limbah tinja, limbah hewan dan limbah dapur dengan anaerobic system atau pengolahan secara biologis dengan menggunakan mahluk hidup berupa bakteri sebagai pencerna limbah. Teknologi yang memanfaatkan proses fermentasi dari sampah organik secara anaerobik adalah biogas. Biogas diproduksi didalam alat biodigester oleh fermentasi anaerobik dengan bantuan bakteri methanogenic. Hasil pengolahan limbah manusia dengan biogas dapat dihasilkan antara lain: gas metan untuk bahan bakar generator dan kompor. Endapan lumpur digunakan untuk pupuk pertanian dan air limpasan disaring dengan tanaman air yang dapat menjadi nutrisi pada kolam ikan.

Alat biogas terbagi atas dua tipe yaitu tipe terapung (Floating Type) dan tipe kubah (Fixed Dome Type). Tipe terapung terdiri atas sumur pencerna dan diatasnya diletakkan drum terapung dari besi terbalik yang berfungsi untuk menampung gas yang dihasilkan oleh digester. Berbeda halnya dengan tipe terapung, tipe kubah berupa digester yang dibangun dengan menggali tanah, kemudian dibuat bangunan setengah lingkaran (kubah) yang kedap udara dari bahan batu bata, pasir dan semen. (http://io.ppi-jepang.org) 


\section{METODE PENELITIAN}

Penelitian ini bertujuan untuk mengkaji sanitasi ekologis pada IPAL Sanimas sehingga menggunakan paradigma kualitatifrasionalistik yaitu berawal dari teori yang dikembangkan ke empiris. Setelah mendapatkan data penelitian, maka dilakukan tahap analisis, berdasarkan parameter-parameter yang telah ditetapkan.

Metode pengumpulan data menggunakan metode purposif sampling yaitu di Kampung Sangkrah RT 04 RW 08. Luas wilayah kampung tersebut adalah $4 \mathrm{~km}^{2}$ dan jumlah penduduk 215 jiwa dengan $40 \mathrm{KK}$. Komposisi penduduk laki-laki 82 jiwa, perempuan 76 jiwa dan anak-anak 67 jiwa. Pada umumnya, penduduk bekerja sebagai buruh dengan rata-rata pendapatan sekitar Rp. 400.000 - Rp. 1.000.000./bulan.

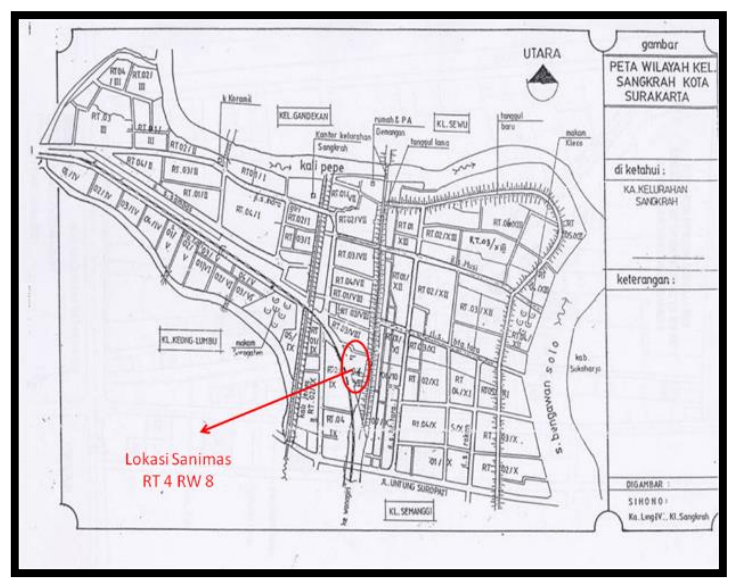

Gambar 1. Lokasi Sanimas Kampung Sangkrah Sumber: Dinas PU Surakarta, 2013

Metode penelitian dengan cara observasi lapangan untuk: (1) pencarian data gambar dan data tekstual; (2) melakukan identifikasi sistim sanitasi pada IPAL Sanimas dan tahap terakhir adalah melakukan verifikasi temuan lapangan yang akan menghasilkan sebuah sistim IPAL Sanimas di Kampung Sangkrah.

\section{HASIL DAN PEMBAHASAN}

\section{Data Lokasi MCK - IPAL Sanimas}

Denah MCK Plus terdiri dari: 5 WC, 3 kamar mandi dan 2 tempat cuci. Pengguna tetap adalah masyarakat Kampung Sangkrah RT 04 RW 08 dengan jumlah penduduk 215 jiwa.

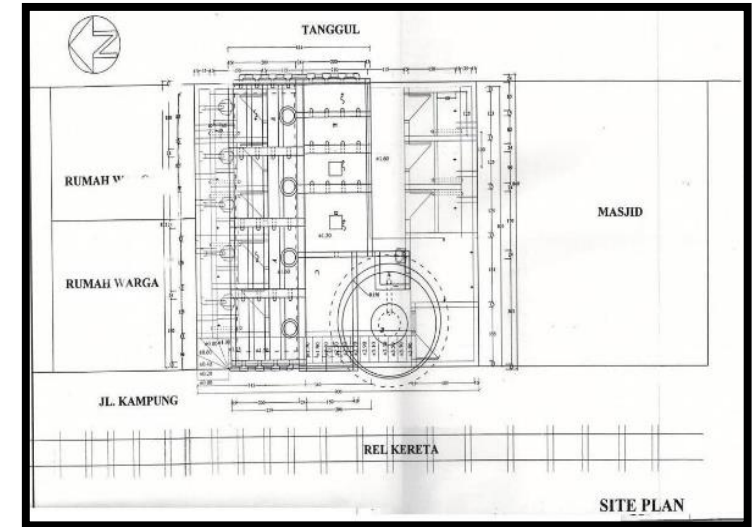

Gambar 2.Lokasi MCK-IPAL Sanimas Sumber: Dinas PU Surakarta, 2013

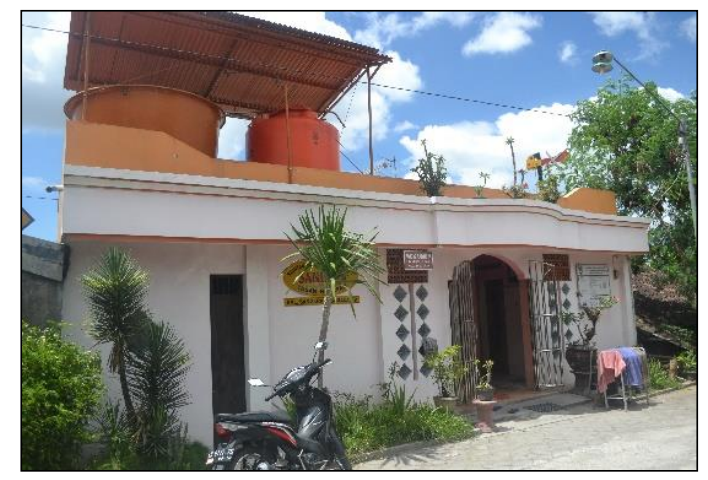

Gambar 3. Foto MCK IPAL Sanimas Sumber: Dokumen 2013

\section{Identifikasi Denah dan Sistim IPAL}

Alat biogas yang digunakan adalah tipe kubah (Fixed Dome Type). Sanimas ini menggunakan sistim DEWATS (Dezentralized Wastewater Treatment System) untuk pengolahan limbah dari toilet komunal.

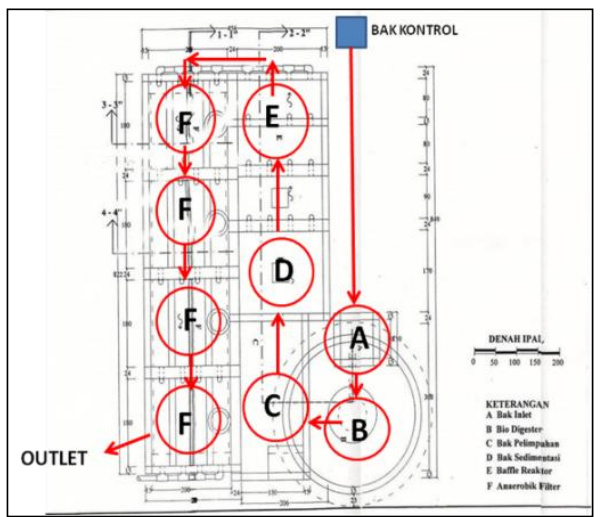

Gambar 4. Potongan IPAL Bak A s/d E $A=$ bak inlet; $B=$ digester; $C=$ bak pelimpah $\mathrm{D}=$ bak settler $\mathrm{E}=$ baffle reactor Sumber: Dinas PU Surakarta, 2013 
Proses yang dihasilkan dari IPAL Sanimas adalah sebagai berikut:

1. Air limbah mengalir ke bak inlet $(A)$ dan kemudian di proses pada bak digester (B).

2. Pada bak digester (B) dihasilkan gas bio yang dapat dimanfaatkan sebagai bahan bakar kompor.

3. Limpahan air dari bak digester dialirkan ke bak pelimpah (C) yang juga sebagai inlet grey water.

4. Air limbah dari bak pelimpah (C) kemudian dialirkan melalui bak settler (D) sebagai bak sedimentasi.

5. Setelah melalui bak sedimentasi maka air limbah difiltrasi menggunakan bakteri sebagai pencerna limbah pada bak baffle reactor $(\mathrm{E})$.

6. Hasil filtrasi dari bak baffle reactor $(\mathrm{E})$ kemudian dilakukan filtrasi akhir menggunakan batu koral supaya lebih jernih yang siap dibuang ke sungai.

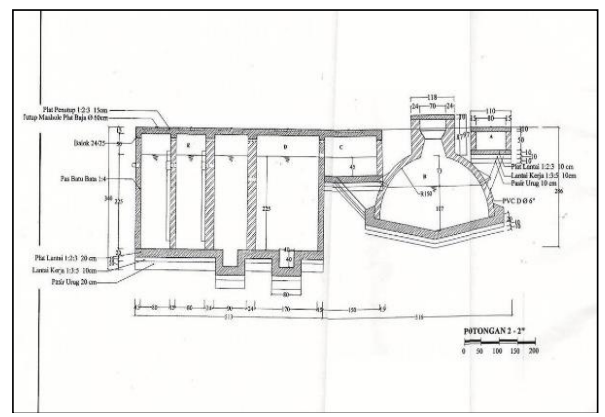

Gambar 5. Potongan IPAL DEWATS Sumber: Dinas PU 2013

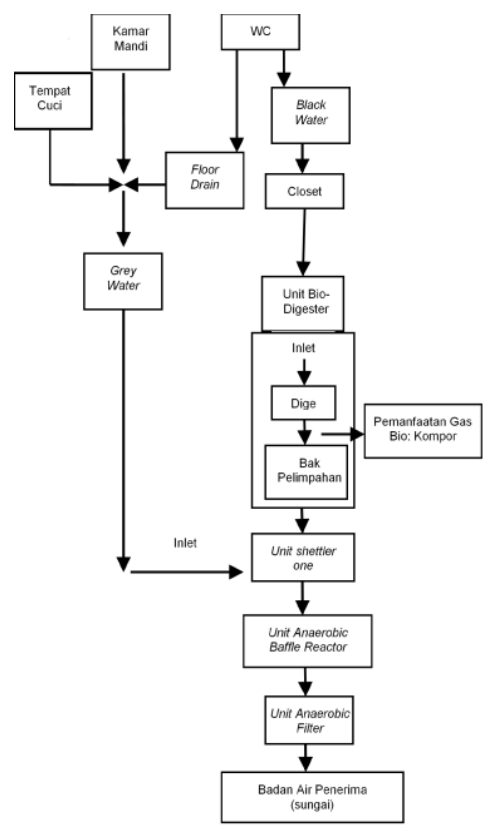

Gambar 6. Diagram IPAL DEWATS

\section{PEMBAHASAN}

Penerapan sanitasi ekologis pada IPAL Sanimas adalah sebagai berikut:

1. Menggunakan anaerobic system yang dilengkapi dengan 5 bak pengolah tinja yang terdiri dari:

a. Unit biodigester: bak pengendapan dan fermentasi limbah untuk menghasilkan gas metan, air limbah dan endapan. Gas metan berfungsi sebagai bahan bakar kompor dan air limbah dengan terlebih dahulu disaring dengan batu koral untuk dibuang ke sungai.

b. Bak pelimpah air limbah untuk dialirkan menuju bak sedimentasi.

c. Bak filterisasi dengan pencerna limbah menggunakan bakteri yang kemudian di filtrasi pada bak terakhir dengan menggunakan batu koral sebagai penjernihan air limbah untuk dibawa badan air penerima yaitu sungai.

2. Limbah grey water dari buangan floor drain tempat cuci dan kamar mandi diolah langsung di bak settler sedangkan limbah tinja (black water) harus terlebih dahulu diolah melalui unit digester. Pelimpahan air limbah dari unit biodigester diolah ke bak settler bersama-sama dengan limbah grey water. Gas bio yang dihasilkan dari biodigester dipergunakan sebagai bahan bakar kompor dan menyalakan lampu petromak.

Berdasarkan monitoring WSP (Water Sanitation Program) terlihat hasil bahwa nilai COD effluent sistim DEWATS paling banyak pada kisaran $80 \mathrm{mg} / \mathrm{L}$. Nilai COD masih dalam batas ambang normal karena nilai baku mutu di Indonesia untuk COD maksimal $100 \mathrm{mg} / \mathrm{L}$. (http://www.borda-sea.org).

Teknologi Sanimas MCK Plus di Kampung Sangkrah berkapasitas 215 jiwa. Standar kapasitas manusia dewasa rataan hasil tinja 0,20 kg/hari/jiwa (Sugiharto 1987 dalam http://www.ipb.ac.id). Berdasarkan standar tersebut maka didapatkan jumlah tinja per harinya dengan rumus :

$$
\Sigma \mathrm{n}=0,2 \mathrm{x}=0,2 \times 215 \text { jiwa }=43 \mathrm{~kg} / \mathrm{hari}
$$

Setiap $80 \mathrm{~kg}$ kotoran sapi yang dicampur dengan 80 liter air dan potongan limbah lainnya dapat menghasilkan $1 \mathrm{~m}^{3}$ biogas Berdasarkan rumus tersebut maka gas yang dihasilkan dari biodigester adalah $0,54 \mathrm{~m}^{3}$ 
setara dengan 0,23 kg gas elpiji (standar: $1 \mathrm{~m}^{3}$ $=0,46 \mathrm{kggaselpiji}$ ).(http://digilib.its.ac.id/public/l TS-paper-19622-3307100030-Paper.pdf)

\section{SIMPULAN DAN SARAN Simpulan}

Sanimas sebagai langkah penanganan untuk sanitasi yang buruk telah berhasil diterapkan di Kampung Sangkrah. Dengan dibangunnya MCK komunal sangat memudahkan warga untuk kegiatan mandi dan cuci yang mayoritas warga tidak mempunyai toilet pribadi. Sistim IPAL DEWATS yang diterapkan sangat sesuai untuk memudahkan pengelolaan dan pemeliharaan kebersihan MCK secara komunal.

Pengolahan black water dan grey water dilakukan secara kolektif dengan biodigester untuk menghasilkan biogas. Dengan hasil biogas sebanyak $0,54 \mathrm{~m} 3$ atau setara $0,23 \mathrm{~kg}$ gas elpiji akan sangat menguntungkan bagi warga sekitar karena dapat menghemat penggunaan gas elpiji. Pemanfaatan hasil pengolahan biodigester berupa biogas belum maksimal karena hanya digunakan oleh pengelola MCK dan salah satu rumah warga saja.

\section{Saran}

Untuk pengolahan limbah grey water belum dimanfaatkan oleh warga. Padahal hasil pengolahan limbah grey water dapat dimanfaatkan untuk budidaya tanaman air atau budidaya ikan yang dapat meningkatkan nilai ekonomi dengan menjual hasil tanaman air atau ikan. Selain itu dengan adanya tanaman air dapat meningkatkan nilai estetika Kampung Sangkrah. Untuk itu perlu pengembangan desain Sanimas dengan memanfaatkan pengolahan limbah grey water.

\section{DAFTAR PUSTAKA}

Dinas PU Kota Surakarta, 2013, Proyek Sanitasi Berbasis Masyarakat 2006, Gambar Kerja

Frick, Heinz, 2007, Penciptaan Keseimbangan di Antara Ekologi dan Perkotaan di Indonesia, Prosiding Seminar Nasional Arsitektur, Universitas Diponegoro, Semarang.

Prihandrijanti, Maria dan Firdayati, Mayrina, 2011, Current Situation and Consideration of Domestic Wastewater Treatment Plant for Big Cities in Indonesia (Case Study: Surabaya and Bandung), Jurnal of Water Sustainability, Vol. 1, 2 September 2011, University of Technology Sydney \& Xi'an University Architecture and Technology.

Yeang, Kenneth, 2006, Ecodesign: Design for Water Conservation, Recycling, Harvesting, etc: Conserving Water Resources,John Wiley and Sons, Ltd, London, pp. 262-267.

http://io.ppi-jepang.org, (Dani, Asep Bayu dan Rumi, Fikri, Biogas Sebagai Peluang Pengembangan Energi Alternatif), INOVASI Online, Edisi vol. 8/XVIII/November 2006, diakses 2 Desember 2012

http://www.borda-sea.org/fileadmin/borda-ea/Knowledge/BORDA\%20Blitz/2012 31 BB\%238web.pdf, diakses 2 Desember 2012

http://ciptakarya.pu.go.id/plp/wsp/, diakses 2 Desember 2012

http://www.ipb.ac.id, (Wendrawan, Fahmi Tri, Prospek Pemanfaatan Limbah Kotoran Manusia Di Asrama TPB-IPB Sebagai Penghasil Energi Alternatif Bio Gas) diakses 11 Desember 2012.

http://digilib.its.ac.id/public/ITS-paper-19622-3307100030-Paper.pdf, (Perencanaan Biodigester Tinja Manusia Dan Kotoran Ternak Skala Komunal Rumah Tangga Di Kecamatan Ngancar Kabupaten Kediri) diakses 11 Desember 2012 